tively occurred two decades before.

This is an important monograph and deserves to be read for the historical questions it raises about nineteenth century science as much as for its definitive account of a forgotten physical theory.

W. H. BROCK

\section{Analytical Geochemistry}

Analytical Geochemistry. By Lord Energlyn and L. Brealey. (Methods in Geochemistry and Geophysics, Vol. 5.) Pp. $x v+426$. (Elsevier: Amsterdam, London and New York, 1971.) £9.25.

This book attempts to describe a wide variety of chemical and physical analytical procedures of use to geochemists. While chemical methods are described in some detail the treatment of physical methods is disappointing, and out of date in many instances.

The introduction contains a curious selection of geochemical topics. Igneous and metamorphic geochemistry are discussed only in terms of classification, with details of the well established "CIPW norm" and "Niggli equivalent norm". Although hydrothermal processes are briefly mentioned there is virtually no reference to modern work, even to such excellent texts as Geochemistry of Hydrothermal Ore Deposits edited by H. L. Barnes. A very brief, dated section on chemical solubility products and an introduction to fluidization phenomena are followed by interesting observations on the role of organic solvents in sedimentary geochemistry. The latter topic reflects the senior author's interests, and includes considerable reference to his own work.

The second chapter outlines the principles of qualitative analysis of rocks and minerals and is particularly noteworthy for the detailed description of the little known technique of membrane colorimetry. This technique incorporates a variety of methods for the transfer of chemical images from flat surfaces of metal, rocks and plants.

Quantitative chemical analysis is covered by the third and fourth chapters. The third chapter describes the main rapid methods of analyses of silicates, carbonates and phosphates in sufficient detail for the book to serve as a bench manual. The fourth chapter is a lengthy account of the chemical determination of minor elements in which the occurrence, detection and estimation of over fifty elements are described element by element.

The fifth to ninth chapters cover emission spectrography, flame photometry, X-ray spectrography and diffraction and fluorimetry. In each case the brief description covers basic principles, equipment and procedure. As an introduction for geologists with a limited chemical background knowledge these chapters may serve some purpose. However, even in this context it would have been useful to outline the relative speed, precision and general applicability of each technique rather than cite limited, specific examples of their application. Some of the pitfalls of these techniques are understated, particularly matrix effects which are of prime importance in optical and X-ray spectrography and in X-ray diffractometry. A fuller description of matrix effects would have been of benefit to the beginner, particularly if ways of circumventing or overcoming such problems were outlined or, at least, referenced. There is, indeed, little reference to modern literature; nothing more recent than 1962 in relation to emission spectrography, or 1961 for $\mathrm{X}$-ray spectrography! The latter is a technique in which enormous advances have been made in the last decade, for example the equipment shown in Figs. 70 and 71 is now essentially obsolete.

The final chapter, on chromatography, is more thorough and includes an outline of the basic principles, followed by detailed descriptions of paper and thinlayer chromatography, gas or vapourphase chromatography and pyrochromatography. The latter technique, developed by Lord Energlyn (W. D. Evans), includes an interesting account of geochemical applications.

In spite of the wide variety of techniques discussed in this book there are notable omissions, particularly important being atomic absorption spectrometry, which is rapidly gaining status as a major analytical technique in geochemistry. The lack of reference to modern work reduces the value of this book as an introductory text, since many physical methods of analysis have changed to such an extent that the methods and hardware of ten years ago are essentially redundant. Priced at $£ 9.25$, this book cannot be considered value for money.

D. M. HiRST

\section{Maths and Music}

The Acoustical Foundations of Music. By John Backus. Pp. xiv +312 . (John Murray: London, March 1971.) £3.50.

MANY physicists have been interested in the physical principles of music, in how sounds and the particular quality of sounds are produced by musical instruments, in the admixture of sounds and the effect of the surroundings on what one hears, and in the many other problems connected with music, including the physiological questions about hearing and the voice. It is a fascinating subject for physicists who are interested in music or musicians who want to have some idea of "how things work".
This book is directed to musicians and particularly to those "with no scientific background and no mathematical equipment past the high school algebra they have already forgotten". The author goes on to say "thus they are representative of musicians generally". Is this so? One hopes not, but even if it is, twenty pages of elementary mechanics, including careful definitions of length, time and mass, seem rather unnecessary. This determination to keep mathematics to a minimum precludes the use of trigonometric functions and logs (although logs are explained in an appendix) and this leads to rather cumbersome explanations of several topics, for example, the various musical scales.

Given this limitation, the author describes the main features of the subject very well, but this has been done before by a number of authors. It is in the discussion and explanation of finer details that both musicians and physicists find most interest, because the fundamentals are in most cases fairly easy, but the exact description of what happens is often extremely complicated. Here the author is concerned to show, without too much complication, how some of these problems can be tackled and the results that have been obtained. $\mathrm{He}$ is also concerned to refute the "fallacies and superstitions that music could better do without". Most of these onslaughts seem to be fair comment but in the case of piano touch there is a point which seems not to have been made. The physicists' argument, strongly expressed by the author, is that when the hammer strikes the string it is "completely separate from the impelling mechanism attached to the key" and that "it follows that the pianist cannot independently control the quality of a single note on the piano by the manner in which he strikes the keys". The first statement is true, but the second does not follow because the stem carrying the hammer will bend and the bending is proportional to the acceleration while the final velocity depends on the integral of the acceleration. It is doubtful whether the experimental work done in the 1920s was of sufficient accuracy to resolve this point and it should be added to the very many unsolved problems which the author points to as requiring further investigation.

This constant reminder of how much work is waiting to be done is one of the very good features of this book, as is the treatment of wind instruments, so often neglected in books of this sort (the author plays the bassoon), and also the extensive bibliography, much of it of recent work, which will so much ease the path of those interested in the pursuit of some of these topics.

J. H. E. Griffiths 